\title{
Atividade enzimática em variedades de cana-de-açúcar cultivadas in vitro sob diferentes níveis de nitrogênio
}

\author{
Virgínia Maria Tenório Sabino Donato(1), Arnóbio Gonçalves de Andrade ${ }^{(2)}$, Eidy Simões de Souza(3), \\ José Geraldo Eugênio de França ${ }^{(3)}$ e Gabriel Alves Maciel ${ }^{(3)}$
}

\begin{abstract}
(1)Rua João Ramos, 285/1801, Graças, CEP 52011-080 Recife, PE. E-mail:vmtsdonato@uol.com.br (2)Universidade Federal Rural de Pernanbuco, Dep. de Química Vegetal, Rua Dom Manoel de Medeiros, s/no, Dois irmãos, CEP 52171-900 Recife, PE. E-mail: arnobio@truenet.com.br (3)Empresa Pernambucana de Pesquisa Agropecuária, Av. Gal. San Martin, 7310, Bongi, Recife, PE. E-mail: eidy@ipa.br, geugenio@terra.com.br, sprra@fisepe.pe.gov.br
\end{abstract}

\begin{abstract}
Resumo - O nitrogênio é considerado o elemento mineral mais abundante nas plantas, sendo componente essencial de biomoléculas e inúmeras enzimas. O objetivo deste trabalho foi avaliar a eficiência no processo de assimilação do nitrogênio e encontrar parâmetros indicativos do potencial de fixação biológica em variedades de cana-de-açúcar (Saccharum officinarum) cultivadas in vitro. Foram utilizadas as variedades de cana-de-açúcar RB 842021, RB 83102, RB 75126, RB 882980 e Co 997, além da Brachiaria arrecta (testemunha), cultivadas in vitro em diferentes níveis de nitrogênio [M1 (9,83 mM), M2 (2,46 mM), M3 (0,49 mM), M4 (0,0 mM)]. Todas as variedades e a cultura testemunha (Brachiaria arrecta) apresentaram atividade da nitrato redutase (NR) constitutiva e também da glutamina sintetase (GS), mesmo na ausência de amônio e nitrato no meio de cultura. A variedade RB 842021 apresentou a maior atividade da nitrato redutase e o maior conteúdo de clorofilas $a$ e $b$, e a variedade RB 882980 a maior atividade da glutamina sintetase nas mesmas condições de cultivo, o que pode representar maior potencial de assimilação do nitrogênio.
\end{abstract}

Termos para indexação: Saccharum, glutamina sintetase, redutase do nitrato, clorofila.

\section{Enzymatic activity in sugar cane varieties cultivated in vitro under nitrogen levels}

\begin{abstract}
Nitrogen is considered the most abundant mineral element in the plants and an essential component to biomolecules and several enzymes. The objective of this work was to estimate nitrogen assimilation efficiency process and to identify biological fixation potential parameters on sugar cane varieties cultivated in vitro. The sugar cane varieties used were RB 842021, RB 83102, RB 75126, RB 882980, CO 997, besides Brachiaria arrecta (witness), cultivated in vitro in different nitrogen levels [M1 (9.83 mM), M2 (2.46 mM), M3 (0.49 mM), M4 (0.0 mM)]. All the varieties and plant witness (Brachiaria arrecta) exhibited redutase nitrate activity and glutamina sintetase, even in the ammonium and nitrate absence culture media. The RB 842021 variety showed the highest activity of nitrate reductase and the higher chlorophyll $a$ and $b$ contents, whereas RB 882980 variety showed the highest glutamine sintetase activity when cultivated without nitrogen, representing a higher potential assimilation of nitrogen.
\end{abstract}

Index terms: Saccharum, glutamina sintetase, nitrate reductase, chlorophyll.

\section{Introdução}

A utilização do nitrogênio atmosférico $\left(\mathrm{N}_{2}\right)$ envolve a integração da fixação e da rota assimilatória do nitrogênio $(\mathrm{N})$ pelo microssimbionte e pela planta hospedeira, respectivamente. Para sustentar o crescimento adequado dos dois organismos, o $\mathrm{N}_{2}$ precisa ser fixado eficientemente e deve envolver mecanismos regulatórios para orientar o fluxo e o intercâmbio de metabólitos entre a planta e o microssimbionte (Cullimore \& Bennett, 1992).
Uma característica peculiar das bactérias fixadoras de $\mathrm{N}_{2}$, mais especificamente da Acetobacter diazotrophicus, é a habilidade de excretar parte do $\mathrm{N}$ fixado no meio (Cojho et al., 1993). Recentemente, determinou-se que o produto do processo de fixação biológica do $\mathrm{N}_{2}$ liberado tanto por Azospirillum spp. como por Acetobacter diazotropicus para a planta hospedeira é o amônio (Christiansen-Weniger \& Vanderleyden, 1994).

A redutase do nitrato (NR) é a enzima catalisadora da conversão do $\mathrm{N}$ inorgânico na forma de nitrato $\left(\mathrm{NO}_{3}{ }^{-}\right)$ 
para a forma de nitrito $\left(\mathrm{NO}_{2}^{-}\right)$. O nitrito formado é exportado para o cloroplasto e, posteriormente, transformado em amônio $\left(\mathrm{NH}_{4}{ }^{+}\right)$pela ação da nitrito redutase (Sanchez \& Heldt, 1990). O amônio produzido é então incorporado em ácidos orgânicos, dando origem aos aminoácidos, a partir de reações subseqüentes catalisadas pelas enzimas glutamina sintetase (GS) e glutamato sintetase (GOGAT). Várias espécies de plantas fixadoras de $\mathrm{N}_{2}$ apresentam atividade da nitrato redutase constitutiva, expressa na ausência de nitrato (Caboche \& Rouzé, 1990). Por sua vez, a fixação biológica do N, segundo Last (1993) e Pearson \& Ji (1994), é um dos processos fisiológicos que envolvem, também, a atividade da glutamina sintetase.

Além de presente em biomoléculas fundamentais, como proteínas e aminoácidos, o $\mathrm{N}$ é constituinte das clorofilas (Mengel \& Kirby, 1987). A estrutura das clorofilas $a$ e $b$ é, basicamente, a mesma. Compõem-se da porção porfirina, constituída de quatro anéis de pirrol ligados por pontes de carbono-hidrogênio. $\mathrm{O}$ íon metálico Mg está inserido no centro da porfirina (Magalhães, 1985). O ácido $\delta$-aminolevulínico, um aminoácido não protéico, cuja via de biossíntese tem como precursor inicial o glutamato, é a molécula precursora da clorofila (Kannangara, 1991). Portanto, a disponibilidade de $\mathrm{N}$ orgânico na forma de glutamato pode influenciar fortemente a capacidade fotossintética das plantas.

O objetivo deste trabalho foi avaliar a eficiência no processo de assimilação do nitrogênio e encontrar parâmetros indicativos do potencial de fixação biológica em variedades de cana-de-açúcar cultivadas in vitro.

\section{Material e Métodos}

As variedades de cana-de-açúcar RB 842021, RB 83102, RB 75126, RB 882980 e Co 997 foram fornecidas pela Estação Experimental de Itapirema da Empresa Pernambucana de Pesquisa Agropecuária (IPA).

No desenvolvimento e condução dos experimentos, estas variedades foram, inicialmente, introduzidas in vitro, a partir do cultivo de ápices caulinares. Posteriormente, foram submetidas a testes de infecção para verificar a presença das bactérias A. diazotrophicus e Herbaspirillum spp., que foram realizados de acordo com Döbereiner et al. (1995).

A Brachiaria arrecta foi introduzida in vitro para servir como testemunha não fixadora do $\mathrm{N}_{2}$ (Urquiaga et al., 1989, 1992). O meio nutritivo básico foi constituído pelos sais do MS descrito por Murashige \& Skoog
(1962), com modificações nos níveis de N, acrescido de $20 \mathrm{~g} \mathrm{~L}^{-1}$ de sacarose. Foram utilizados o MS completo com 9,83 mM, além dos demais com a concentração de $\mathrm{N}$ reduzida para 2,46, 0,49 e $0,0 \mathrm{mM}$.

O experimento foi constituído de 24 tratamentos com dez repetições. Os tratamentos consistiram na combinação das cinco variedades de cana-de-açúcar e da testemunha (Brachiaria arrecta), com quatro níveis de nitrogênio $(9,83,2,46,0,49$ e $0,0 \mathrm{mM})$, conduzido em delineamento inteiramente casualizado. $\mathrm{O}$ experimento foi mantido em sala de crescimento com temperatura de $24 \pm 1^{\circ} \mathrm{C}$ e fotoperíodo de 16 horas, onde permaneceu por 45 dias. Após este período, foram avaliados a massa da matéria fresca, o conteúdo de pigmentos fotossintéticos e a atividade das enzimas nitrato redutase (NR) e glutamina sintetase (GS), procurando relacionálos com a fixação biológica do nitrogênio. Os resultados foram submetidos à análise de variância e as médias comparadas pelo teste de Tukey a $5 \%$ de probabilidade.

A atividade da nitrato redutase foi determinada na parte aérea das plantas de cana-de-açúcar após 45 dias de cultivo in vitro. Utilizou-se o método in vivo descrito por Jaworski (1971), que se baseia no princípio de que a quantidade de nitrito liberada por fragmentos de tecidos vivos num tampão, na presença de um agente permanente (propanol) e do substrato $\left(\mathrm{NO}_{3}{ }^{-}\right)$, reflete a atividade potencial da NR in situ (Hageman \& Reed, 1980). A atividade da enzima é calculada pela quantidade de $\mathrm{NO}_{2}{ }^{-}$liberada pelos tecidos vegetais na solução de incubação, sendo expressa em nmoles de $\mathrm{NO}_{2}^{-} \mathrm{h}^{-1} \mathrm{~g}^{-1}$ de matéria fresca.

Após serem removidas do meio de cultura, as plantas foram cuidadosamente lavadas em água destilada, secadas com papel toalha e, em seguida, cortadas rapidamente com uma tesoura cirúrgica, de modo a obterse uma amostra com $0,2 \mathrm{~g}$ de matéria fresca.

Amostras em triplicatas dos fragmentos de tecido de parte aérea das plantas, pesando $0,2 \mathrm{~g}$, foram incubadas

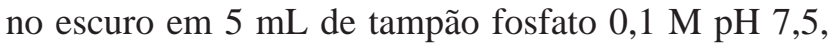
contendo n-propanol a $2 \%$ e $0,02 \mathrm{M}$ de $\mathrm{KNO}_{3}$, e mantidas em banho-maria a $30^{\circ} \mathrm{C}$, por 60 minutos. Após o período de incubação, foram retiradas alíquotas de $0,4 \mathrm{~mL}$ da solução de incubação de cada amostra e recolhidas em tubos de ensaio devidamente identificados, onde foram adicionados $0,3 \mathrm{~mL}$ de sulfanilamida a $1 \%$, $0,3 \mathrm{~mL}$ de n-naftil-etileno-diamino a $0,02 \%$. As alíquotas permaneceram em repouso por 20 minutos e, então, acrescentou-se $4 \mathrm{~mL}$ de água destilada. A absorbância foi medida em espectrofotômetro a $540 \mathrm{~nm}$ e a determi- 
nação da concentração de $\mathrm{NO}_{2}^{-}$, obtida a partir de uma curva padrão de $\mathrm{NO}_{2}^{-}$.

Na extração da enzima GS, amostras em triplicata de fragmentos de tecido da parte aérea das plantas, pesando $1 \mathrm{~g}$, foram maceradas em $\mathrm{N}_{2}$ líquido. Em seguida, foram adicionados $8 \mathrm{~mL}$ do tampão de extração, constituído de tampão imidazol-HCl pH 7,5, $\mathrm{MgSO}_{4} 0,1 \mathrm{M} \mathrm{e}$ mercaptoetanol, homogeneizando-se as amostras. Em seguida, o homogeneizado foi passado por gase e o filtrado recolhido em tubos de centrífuga imersos em gelo. Em seguida, foram centrifugados por 15 minutos, a $0^{\circ} \mathrm{C}$, a $15.000 \mathrm{~g}$ e o sobrenadante foi recolhido e conservado em gelo.

Para a reação adicionou-se em tubos de ensaio $0,2 \mathrm{~mL}$ de tampão imidazol- $\mathrm{HCl}$ 0,5 M pH 7,5; $0,1 \mathrm{~mL}$ de mercaptoetanol 0,1 M; 0,1 mL de $\mathrm{MgSO}_{4} 0,4 \mathrm{M} ; 0,1 \mathrm{~mL}$ de hidroxilamina $0,1 \mathrm{M} \mathrm{pH} 6,5 ; 0,1 \mathrm{~mL}$ de ATP $0,1 \mathrm{M}$; $0,1 \mathrm{~mL}$ de glutamato $0,5 \mathrm{M} \mathrm{pH}$ 7,5; 0,3 g de amostra e $1,0 \mathrm{~mL}$ de água destilada. Em seguida, as amostras foram incubadas a $30^{\circ} \mathrm{C}$ por 30 minutos. Após esse período, a reação foi interrompida com adição de $1,5 \mathrm{~mL}$ do reagente constituído de cloreto férrico e ácido tricloroacético dissolvidos em $\mathrm{HCl} 0,5 \mathrm{~N}$. A absorbância das amostras foi medida em $540 \mathrm{~nm}$, utilizando como padrão o $\gamma$-glutamil mono-hidroxamato. A atividade da GS foi expressa em mmoles de $\gamma$-glutamil monohidroxamato produzido por minuto por grama de matéria fresca (Farnden \& Robertson, 1980).

Na determinação do conteúdo de clorofila, amostras de $0,2 \mathrm{~g}$ de tecido foliar fresco, coletadas em triplicatas foram postas em tubos com tampa contendo $10 \mathrm{~mL}$ de acetona $80 \%$ (v/v) em água, onde permaneceram por 24 horas em câmara fria, protegidas da luz. Após 24 horas, os extratos foram filtrados e a leitura efetua- da em 663 e $645 \mathrm{~nm}$ para clorofilas $a$ e $b$, respectivamente. As determinações da clorofila $\left(\mathrm{mg} \mathrm{gmf}^{-1}\right)$ basearam-se nas equações abaixo relacionadas, segundo Whitham et al. (1971):

$$
\begin{aligned}
& \text { Clorofila } a=\frac{\left(12,7 \times \mathrm{A}_{663}-2,69 \times \mathrm{A}_{645}\right) \mathrm{V}}{1000 \mathrm{MMF}} \\
& \text { Clorofila } b=\frac{\left(22,9 \times \mathrm{A}_{645}-4,68 \times \mathrm{A}_{663}\right) \mathrm{V}}{1000 \mathrm{MMF}}
\end{aligned}
$$

em que A é a absorbância no comprimento de onda indicado, $\mathrm{V}$ é o volume final do extrato clorofila-acetona, e MMF é a massa da matéria fresca em gramas do material vegetal utilizado.

\section{Resultados e Discussão}

\section{Atividade da nitrato redutase}

A atividade da nitrato redutase variou significativamente entre as variedades, apenas no meio de cultura contendo 9,83 mM de N (M1), obtendo-se o valor máximo na variedade RB 83102, que não diferiu da Brachiaria (testemunha), e os valores mais baixos nas variedades RB 842021 e RB 75126 (Tabela 1). Nos demais meios de cultura não houve diferença significativa entre as variedades de cana-de-açúcar e a Brachiaria (testemunha).

Na maioria das espécies a atividade da nitrato redutase é baixa ou não detectável quando cultivadas na ausência de nitrato (Andrews et al., 1990). Por outro lado, observou-se em todas as variedades de cana-de-açúcar, e até mesmo na cultura testemunha, valores significativos da atividade desta enzima em meios de cultura com muito baixa concentração ou desprovido de nitrogênio. A variedade RB 842021 apresentou valor máxi-

\begin{tabular}{|c|c|c|c|c|c|c|}
\hline $\mathrm{N}(\mathrm{mM})^{(2)}$ & RB 83102 & RB 842021 & RB 882980 & Co 997 & RB 75126 & Brachiaria \\
\hline & \multicolumn{6}{|c|}{ Atividade da nitrato redutase $(\mu \text { moles } / \mathrm{gmf} / \mathrm{h})^{(3)}$} \\
\hline 9,83 & $206,31 \mathrm{aA}$ & $62,16 \mathrm{cAB}$ & $104,96 \mathrm{bcA}$ & $107,26 \mathrm{bcA}$ & $50,90 \mathrm{cA}$ & $161,26 \mathrm{abA}$ \\
\hline 2,46 & $50,90 \mathrm{aB}$ & $55,41 \mathrm{aB}$ & $55,41 \mathrm{aA}$ & $107,21 \mathrm{aA}$ & $55,41 \mathrm{aA}$ & $102,70 \mathrm{aA}$ \\
\hline 0,49 & $50,90 \mathrm{aB}$ & $134,23 \mathrm{aA}$ & $71,17 \mathrm{aA}$ & $109,46 \mathrm{aA}$ & $91,44 \mathrm{aA}$ & $89,19 \mathrm{aA}$ \\
\hline \multirow[t]{2}{*}{0,00} & $46,40 \mathrm{aB}$ & $86,94 \mathrm{aAB}$ & $44,14 \mathrm{aA}$ & $48,65 \mathrm{aA}$ & $77,93 \mathrm{aA}$ & $95,95 \mathrm{aA}$ \\
\hline & \multicolumn{6}{|c|}{ Atividade da glutamina sintetase (nmoles/g/min) } \\
\hline 9,83 & $97,99 \mathrm{bA}$ & $220,09 \mathrm{aA}$ & $223,17 \mathrm{aA}$ & $187,76 \mathrm{aA}$ & $88,75 \mathrm{bA}$ & $204,69 \mathrm{aA}$ \\
\hline 2,46 & $62,84 \mathrm{bAB}$ & $163,64 \mathrm{aB}$ & $152,36 \mathrm{aB}$ & $99,50 \mathrm{bCB}$ & $63,61 \mathrm{bAB}$ & $196,99 \mathrm{aA}$ \\
\hline 0,49 & $59,24 \mathrm{bAB}$ & $125,16 \mathrm{aCB}$ & $137,99 \mathrm{aB}$ & $136,45 \mathrm{aB}$ & $47,96 \mathrm{bAB}$ & $136,96 \mathrm{aB}$ \\
\hline 0,00 & $37,69 \mathrm{~dB}$ & $101,56 \mathrm{abC}$ & $130,80 \mathrm{aB}$ & $81,03 \mathrm{bcC}$ & $27,94 \mathrm{~dB}$ & $104,63 \mathrm{abB}$ \\
\hline
\end{tabular}
mo da atividade da NR em relação às demais varieda-

Tabela 1. Atividade das enzimas nitrato redutase e glutamina sintetase em folhas de variedades de cana-de-açúcar cultivadas in vitro, por 45 dias, em razão de níveis de nitrogênio ${ }^{(1)}$.

${ }^{(1)}$ Médias seguidas pela mesma letra, minúscula para variedades e maiúscula para níveis de $\mathrm{N}$, não diferem entre si a $5 \%$ de probabilidade pelo teste Tukey. ${ }^{(2)}$ Meio com sais do MS, acrescido de sacarose e diferentes concentrações de nitrogênio. ${ }^{(3)}$ gmf: grama de matéria fresca. 
des quando cultivada sem $\mathrm{N}$, com exceção da testemunha (Tabela 1). Da mesma forma, Timpo \& Neyra (1983) encontraram, em folhas de Phaseolus vulgaris, valores significativos de atividade da NR em plantas cultivadas na presença de $\mathrm{NH}_{4}{ }^{+}$ou uréia como fontes exclusivas de nitrogênio.

A nitrato redutase é uma enzima induzida, caracteristicamente, pelo seu substrato (Redinbaugh \& Campbell, 1991). A presença de uma nitrato redutase constitutiva, expressa na ausência de nitrato, ocorre em várias espécies de plantas fixadoras de $\mathrm{N}_{2}$, como a soja e o feijão (Andrews et al.,1990; Caboche \& Rouzé, 1990), o que, possivelmente, pode justificar os resultados obtidos neste trabalho, considerando que as variedades de canade-açúcar avaliadas estavam associadas às bactérias fixadoras do nitrogênio atmosférico.

Huber et al. (1992) relacionaram a taxa fotossintética à atividade da nitrato redutase. A variedade RB 842021, quando cultivada sem nitrogênio (M4) (Tabela 1), apresentou a maior atividade da nitrato redutase em relação as demais variedades e mostrou também o maior conteúdo de clorofilas $a$ e $b$ (Tabela 2) e massa de matéria fresca, nas mesmas condições de cultivo (Tabela 3 ).

Em plantas de milho, a atividade da enzima nitrato redutase não foi influenciada pela inoculação com bactérias diazotróficas, provavelmente, pela competição das bactérias com a nitrato redutase por carboidratos provenientes da fotossíntese. No entanto o incremento de peso e do conteúdo de $\mathrm{N}$ nos grãos mostraram que as bactérias podem ter influenciado o sistema de absorção e utilização deste elemento (Machado et al., 1998).

É possível inferir que as bactérias fixadoras de $\mathrm{N}_{2}$ influenciaram a atividade das enzimas do metabolismo do $\mathrm{N}$ nas variedades de cana-de-açúcar estudadas, per- mitindo a incorporação do $\mathrm{N}$ e incrementando o transporte deste elemento para a parte aérea.

\section{Atividade da enzima glutamina sintetase (GS)}

A atividade da GS nas folhas variou significativamente entre as variedades conforme o nível de $\mathrm{N}$ utilizado (Tabela 1). Nos meios de cultura contendo 9,83 e 0,49 mM de N, M1 e M3, respectivamente, apenas as variedades RB 75126 e RB 83102 diferiram das demais. Praticamente, todas as variedades apresentaram atividade máxima no meio MS completo (9,83 mM de N) (Tabela 1). Magalhães \& Huber (1991) constataram que a atividade da GS em raízes de tomate, milho e arroz foi maior quando cultivadas no meio MS completo. Em couve, a atividade da mesma enzima também aumentou em resposta à quantidade de $\mathrm{N}$ utilizada, independentemente da fonte (Zago, 1997).

Em tecidos foliares ou clorofilados, são encontrados dois tipos da enzima glutamina sintetase, que estão localizadas no cloroplasto $\left(\mathrm{GS}_{2}\right)$ e no citossol $\left(\mathrm{GS}_{1}\right)$ (Sechley et al., 1992). A atividade da GS foliar corresponde, em grande parte, à isoenzima dos cloroplastos que desempenha um papel fundamental na assimilação do $\mathrm{NH}_{4}{ }^{+}$, na fotorrespiração e na redução do $\mathrm{NO}_{3}{ }^{-}$(Sechley et al., 1992; Oaks, 1994). Neste trabalho, as variedades RB 882980, RB 842021 e a testemunha apresentaram maior atividade da enzima GS em relação às demais variedades e não diferiram significativamente entre si, quando cultivadas em meio de cultura desprovido de nitrogênio.

Embora as plantas utilizadas nos experimentos tenham sido provenientes da cultura de ápices caulinares, testes de infecção revelaram a presença de bactérias, mais especificamente o Hebaspirillum spp. A B. arrecta, utilizada como cultura testemunha não fixadora do $\mathrm{N}_{2}$

Tabela 2. Conteúdo de clorofilas $a$ e $b$ em folhas frescas de variedades de cana-de-açúcar cultivadas in vitro, por 45 dias, em razão de níveis de nitrogênio ${ }^{(1)}$.

\begin{tabular}{|c|c|c|c|c|c|c|}
\hline $\mathrm{N}(\mathrm{mM})^{(2)}$ & RB 83102 & RB 842021 & RB 882980 & Co 997 & RB 75126 & Brachiaria \\
\hline \multicolumn{7}{|c|}{ Clorofia $a(\mu \mathrm{g} / \mathrm{gmf})^{(3)}$} \\
\hline 9,83 & $5,90 \mathrm{bA}$ & $10,50 \mathrm{abAB}$ & $10,00 \mathrm{abA}$ & $10,06 \mathrm{abA}$ & $9,90 \mathrm{abA}$ & $12,17 \mathrm{aA}$ \\
\hline 2,46 & $7,03 \mathrm{aA}$ & $8,86 \mathrm{aAB}$ & $9,86 \mathrm{aA}$ & $9,90 \mathrm{aA}$ & $8,96 \mathrm{aAB}$ & $10,60 \mathrm{aA}$ \\
\hline 0,49 & $6,60 \mathrm{aA}$ & $6,83 \mathrm{aB}$ & $6,36 \mathrm{aA}$ & $9,20 \mathrm{aA}$ & $6,20 \mathrm{aAB}$ & $9,43 \mathrm{aA}$ \\
\hline 0,00 & $6,00 \mathrm{bA}$ & $13,10 \mathrm{aA}$ & $6,10 \mathrm{bA}$ & $6,90 \mathrm{bA}$ & $4,60 \mathrm{bB}$ & $8,03 \mathrm{abA}$ \\
\hline \multicolumn{7}{|c|}{ Clorofia $b(\mu \mathrm{g} / \mathrm{gmf})^{(3)}$} \\
\hline 9,83 & $2,03 \mathrm{bA}$ & $3,63 \mathrm{abAB}$ & $3,70 \mathrm{abA}$ & $3,40 \mathrm{abA}$ & $3,47 \mathrm{abA}$ & $4,83 \mathrm{a} \mathrm{A}$ \\
\hline 2,46 & $2,57 \mathrm{aA}$ & $2,93 \mathrm{aAB}$ & $3,40 \mathrm{aA}$ & $3,40 \mathrm{aA}$ & $3,10 \mathrm{aA}$ & $4,10 \mathrm{aA}$ \\
\hline 0,49 & $2,33 \mathrm{aA}$ & $2,37 \mathrm{aB}$ & $2,37 \mathrm{aA}$ & $3,10 \mathrm{aA}$ & $3,07 \mathrm{aA}$ & $3,73 \mathrm{aA}$ \\
\hline 0,00 & $2,03 \mathrm{bA}$ & $4,67 \mathrm{aA}$ & $2,13 \mathrm{bA}$ & $2,53 \mathrm{bA}$ & $2,06 \mathrm{bA}$ & $3,57 \mathrm{abA}$ \\
\hline
\end{tabular}

${ }^{(1)}$ Médias seguidas pela mesma letra, minúscula para variedades e maiúscula para níveis de $\mathrm{N}$, não diferem entre si a 5\% de probabilidade pelo teste Tukey. ${ }^{(2)}$ Meio com sais do MS, acrescido de sacarose e diferentes concentrações de nitrogênio. ${ }^{(3)}$ gmf: grama de matéria fresca. 
(Urquiaga et al., 1989, 1992), apresentou, no entanto, bom potencial de fixação do $\mathrm{N}_{2}$, pois quando cultivada na ausência de $\mathrm{N}$, o ganho de biomassa foi crescente e apresentou um dos maiores conteúdos de clofilas $a$ e $b$, além de mostrar atividade da NR e GS (Tabela 3).

Provavelmente, a atividade da GS encontrada nas variedades de cana-de-açúcar e na testemunha, quando cultivadas sem $\mathrm{N}$, foi determinada por causa do $\mathrm{N}$ liberado pelo processo de fixação biológica, pois este é um dos processos fisiológicos que envolvem a GS citosólica (Last, 1993; Pearson \& Ji, 1994). Machado et al. (1998) observaram valores superiores na atividade da enzima glutamina sintetase em folhas e raízes de milho cultivado com baixo nível de nitrogênio. Os autores atribuíram este resultado ao incremento da disponibilidade de amônio liberado pelas bactérias fixadoras. Da mesma forma, a maior atividade da enzima GS encontrada nas variedades RB 882980 e RB 842021 pode estar relacionada ao maior incremento de amônio por parte do processo de fixação biológica.

A glutamina sintetase é uma enzima limitante do crescimento e do uso do $\mathrm{N}$ nas plantas (Lam et al., 1995). A massa da matéria seca foi reduzida em $45 \%$ no meio sem nitrogênio (M4) em relação ao meio completo (M1), após 45 dias de cultivo para a variedade RB 842021 (Tabela 3). No entanto, uma redução de aproximadamente $54 \%$ na atividade da GS, do M1 ao M4, na mesma variedade, não teve impacto no conteúdo de clorofilas $a$ e $b$. Em plantas de cevada, observou-se que uma redução de $50 \%$ na atividade da GS não causou impacto no conteúdo total de clorofila, sobre a massa de matéria fresca ou na razão massa de matéria fresca/massa de matéria seca. No entanto, a produção de grãos foi, consideravelmente, reduzida (Häusler et al., 1994).

\section{Conteúdo de clorofila}

Os conteúdos de clorofilas $a$ e $b$ não variaram entre as variedades e a testemunha nos meios de cultura M2 e M3, com 2,46 e 0,49 mM de $\mathrm{N}$, respectivamente.
Entre os níveis de N, o efeito estimulador máximo foi observado no meio de cultura com $9,83 \mathrm{mM}$ na variedade RB 75126, que coincidiu com a maior redução no meio de cultura desprovido de nitrogênio. Nas variedades RB 83102, Co 997, RB 882980 e testemunha não houve diferença significativa entre os níveis de nitrogênio. No entanto, na variedade RB 842021, o meio de cultura desprovido de $\mathrm{N}$ promoveu maior conteúdo de clorofilas $a$ e $b$ (Tabela 2).

A clorofila tem como precursor inicial o glutamato (Kannangara, 1991). Assim, a disponibilidade de $\mathrm{N}$ pode influenciar decisivamente a capacidade fotossintética das plantas. Segundo Shadchina \& Dmitrieva (1995), o conteúdo de clorofila das folhas representa um parâmetro apropriado na avaliação da aquisição de $\mathrm{N}$ pelas plantas, sob diferentes condições ambientais.

Ao dosar o conteúdo de clorofilas $a$ e $b$ das variedades de cana-de-açúcar cultivadas in vitro, sob diferentes níveis de $\mathrm{N}$, buscou-se encontrar um parâmetro indicativo da eficiência das diferentes variedades, no processo de fixação biológica de $\mathrm{N}$ já que, segundo vários autores (Schubert, 1986; Cojho et al., 1993), as bactérias fixadoras liberam, para a planta hospedeira, $\mathrm{N}$ na forma de amônio. Então, quanto mais amônio liberado, maior a disponibilidade de $\mathrm{Ne}$, conseqüentemente, mais clorofila.

A variedade com maior ganho de biomassa, durante os 45 dias de cultivo, no meio de cultura com maior nível de $\mathrm{N}(9,83 \mathrm{mM})$, apresentou o menor conteúdo de clorofilas $a$ e $b$ (Tabela 3). Em folhas de milho e trigo, o conteúdo máximo de pigmentos fotossintéticos foi observado nas plantas que apresentaram o maior crescimento vegetativo (Stancheva \& Dinev, 1995). No meio de cultura desprovido de $\mathrm{N}$ não houve diferença. Entretanto, a variedade com maior acúmulo de biomassa (RB 842021) também mostrou o maior conteúdo de clorofilas $a$ e $b$ nas mesmas condições de cultivo.

Tabela 3. Massa da matéria fresca (g) acumulada em variedades de cana-de-açúcar, após 45 dias de cultivo in vitro em meios de cultura, em razão de níveis de nitrogênio ${ }^{(1)}$.

\begin{tabular}{lllllll}
\hline $\mathrm{N}(\mathrm{mM})^{(2)}$ & RB 83102 & RB 842021 & RB 882980 & Co 997 & RB 75126 & Brachiaria \\
\hline 9,83 & $3,45 \mathrm{aA}$ & $2,85 \mathrm{aA}$ & $2,46 \mathrm{abA}$ & $2,37 \mathrm{abA}$ & $1,34 \mathrm{bcA}$ & $0,90 \mathrm{cA}$ \\
2,46 & $1,70 \mathrm{abB}$ & $1,91 \mathrm{abAB}$ & $2,69 \mathrm{aA}$ & $1,58 \mathrm{abAB}$ & $1,22 \mathrm{bA}$ & $0,99 \mathrm{bA}$ \\
0,49 & $1,98 \mathrm{aB}$ & $1,65 \mathrm{aB}$ & $1,66 \mathrm{aAB}$ & $1,38 \mathrm{aAB}$ & $1,59 \mathrm{aA}$ & $0,76 \mathrm{aA}$ \\
0,00 & $1,17 \mathrm{aB}$ & $1,56 \mathrm{aB}$ & $1,23 \mathrm{aB}$ & $1,12 \mathrm{aB}$ & $1,01 \mathrm{aA}$ & $0,53 \mathrm{aA}$ \\
\hline
\end{tabular}

${ }^{(1)}$ Médias seguidas pela mesma letra, minúscula para variedades e maiúscula para níveis de $\mathrm{N}$, não diferem entre si a $5 \%$ de probabilidade pelo teste Tukey. ${ }^{(2)}$ Meio com sais do MS, acrescido de sacarose e diferentes concentrações de nitrogênio. 
A determinação do conteúdo de clorofila em folhas de trigo representou um parâmetro apropriado para a avaliação da aquisição de $\mathrm{N}$ pelas plantas e, além disso, pôde fornecer um diagnóstico confiável a respeito das condições nutricionais das plantas (Shadchina \& Dmitrieva, 1995).

Condições de crescimento e fatores ambientais podem modificar a razão clorofila $a / b$ das folhas, podendo, por exemplo, variar de acordo com a intensidade luminosa a que as plantas estão expostas (Majerowicz, 1997). Nas plantas submetidas a elevadas intensidade luminosa, a razão clorofila $a / b$ encontra-se em torno de $3,2-4,0$, ao passo que em baixa intensidade luminosa esta razão é de cerca de 2,5-2,8 (Lichtenthaler, 1987). Nas folhas da maioria das variedades de cana-de-açúcar utilizadas no presente trabalho, a razão clorofila $a / b$ oscilou em torno de 2,6-2,95, valores característicos, portanto, de condições nas quais prevalece baixa intensidade luminosa. No entanto, na variedade RB 842021 a razão clorofila $a / b$ oscilou em torno de 2,7-3,6.

\section{Conclusões}

1. A Brachiaria arrecta não deve ser utilizada como cultura testemunha não fixadora do nitrogênio atmosférico.

2. A redução nos níveis de nitrogênio não afeta significativamente o conteúdo das clorofilas $a$ e $b$ das variedades.

3. A atividade constitutiva da nitrato redutase e da glutamina sintetase está presente nas variedades de cana-de-açúcar e planta testemunha, mesmo na ausência de nitrogênio.

4. As variedades RB 842021 e RB 882980 são mais eficientes no processo de assimilação do nitrogênio.

5. Os parâmetros avaliados podem ser utilizados como indicativo do potencial de fixação biológica do nitrogênio em plantas.

\section{Referências}

ANDREWS, M.; FARIA, S.M. de; McINROY, S.G.; SPRENT, J.I. Constitutive nitrate reductase activity in the leguminosae. Phytochemistry, v.29, p.49-54, 1990.

CABOCHE, M.; ROUZÉ, P. Nitrate reductase: a target for molecular and cellular studies in higher plants. Trends in Genetics, v.6, p.187-191, 1990.

CHRISTIANSEN-WENIGER, C.; VANDERLEYDEN, J. Amonium-excreting Azospirillum sp. became intracellulary established in maize (Zea mays L.) to nodules. Biology and Fertility of Soils, v.17, p.1-8, 1994.
COJHO, E.H.; REIS, V.M.; SCHENBREG, A.C.G.; DÖBEREINER, $\mathrm{J}$. Interactions of Acetobacter diazotrophicus with an amylolytic yeast in nitrogen-free batch culture. FEMS Microbiology Letters, v.106, p.341-346, 1993.

CULLIMORE, J.V.; BENNETT, M.J. Nitrogen assimilation in the legumine root nodule: current status of the molecular biology of the plant enzymes. Canadian Journal of Microbiology, v.38, p.461466, 1992.

DÖBEREINER, J.; BALDANI, V.L.D.; BALDANI, J.I. Como isolar e identificar bactérias diazotróficas de plantas não-leguminosas. Brasília: Embrapa-CNPAB, 1995. 60p.

FARNDEN, K.J.S.; ROBERTSON, J.G. Methods for studying enzyme involved in metabolism related to nitrogenase. In: BERGERSEN, F.J. (Ed.). Methods for evaluating biological nitrogen fixation. Chichester: John Wiley \& Sons, 1980. p.279-286.

HAGEMAN, R.H.; REED, A.J. Nitrate reductase from higher plants. San Diego: Academic Press, 1980. p.270-280. (Methods in Enzymology, v.69).

HÄUSLER, R.E.; BLACKWELL, R.D.; LEA, P.J.; LEEGOOD, R.C. Control of photosynthesis in barley leaves with reduced activities of glutamine synthetase or glutamate syntase: I. Plant characteristics and changes in nitrate, ammonium and amino acids. Planta, v.194, p.406-417, 1994.

HUBER, S.C.; HUBER, J.L.; CAMPBELL, W.H.; REDINBAUGH, M.G. Comparative studies of light modulation of nitrate reductase and sucrose-phosphate synthase activities in spinach leaves. Plant Physiology, v.100, p.706-712, 1992.

JAWORSKI, E.G. Nitrate reductase assay in intact plant tissues. Biochemical and Biophysical Research Communications, v.43, p.1274-1279, 1971.

KANNANGARA, C.G. Biochemistry and molecular biology of chlorophyll synthesis. In: BOGORAD, L.; VASIL, I.K. (Ed.). Cell culture and somatic cell genetics of plants. San Diego: Academic Press, 1991. v.7B, p.301-322.

LAM, H.-M.; COSCHIGANO, K.; OLIVEIRA, I.C.; MELOOLIVEIRA, R.; TJADEN, G.; OLIVEIRA, I.; NGAI, N.; HSIEH, M.-H.; CORUZZI, G. Use of arabidopsis mutants and genes to study amide and amino acid biosynthesis. Plant Cell, v.7, p.887898, 1995.

LAST, R.L. The genetics of nitrogen assimilation and amino acid biosynthesis in flowering plants: progress and prospects. Internatinal Review of Cytology, v.143, p.297-330, 1993.

LICHTENTHALER, H.K. Chlorophylls and carotenoids: Pigments of photosynthetic biomembranes. San Diego: Academic Press, 1987. p.350-382. (Methods in Enzymology, v.148).

MACHADO, A.T.; SODEK, L.; DÖBEREINER, J.; REIS, V.M. Efeito da adubação nitrogenada e da inoculação com bactérias diazotróficas no comportamento bioquímico da cultivar de milho Nitroflint. Pesquisa Agropecuária Brasileira, v.33, p.961-970, 1998. MAGALHÃES, A.C.N. Fotossíntese. In: FERRI, M.G. (Ed.). Fisiologia vegetal. São Paulo: EPU, 1985. v.1, cap.3, p.117-166.

MAGALHÃES, J.R.; HUBER, D.M. Response of ammonium assimilation enzymes to nitrogen form treatments in different plant species. Journal of Plant Nutrition, v.14, p.175-185, 1991. 
MAJEROWICZ, N. Crescimento, assimilação e teores de compostos nitrogenados em plantas de Catasetum fibriatum (Morren) Lindl. (Orchidaceae) cultivadas in vitro com diferentes fontes de nitrogênio. 1997. 133p. Tese (Doutorado) - Universidade de São Paulo, São Paulo.

MENGEL, K.; KIRKBY, E.A. Principles of plant nutrition. 4th ed. Bern: International Potash Institute, 1987. 687p.

MURASHIGE, T.; SKOOG, F.A. Revised medium for rapid growth and bioassays with tobacco tissue cultures. Physiologia Plantarum, v.15, p.473-497, 1962.

OAKS, A. Primary nitrogen assimilation in higher plants and its regulation. Canadian Journal of Botany, v.72, p.739-750, 1994.

PEARSON, J.; JI, Y.-M. Seasonal variation of leaf glutamine synthetase isoforms in temperate deciduous trees strongly suggests different functions for the enzymes. Plant Cell and Environment, v.17, p.1331-1337, 1994.

REDINBAUGH, M.G.; CAMPBELL, W.H. Higher plant responses to environmental nitrate. Physiologia Plantarum, v.82, p.640-650, 1991.

SANCHEZ, J.; HELDT, W.H. On the regulation of spinach nitrate reductase. Plant Physiology, v.92, p.684-689, 1990.

SCHUBERT, K.R. Products of biological nitrogen fixation in higher plants: synthesis, transport, and metabolism. Annual Review of Plant Physiology and Plant Molecular Biology, v.37, p.539-574, 1986.

SECHLEY, K.A.; YAMADA, T.; OAKS, A. Compartimentation of nitrogen assimilation in higher plants. Internatinal Review of Cytology, v.134, p.85-163, 1992.
SHADCHINA, T.M.; DMITRIEVA, V.V. Leaf chlorophyll content as a possible diagnostic mean for the evaluation of plant nitrogen uptake from the soil. Journal of Plant Nutrition, v.18, p.14271437,1995

STANCHEVA, I.; DINEV, N. Response of wheat and maize to different nitrogen sources: II. Nitrate reductase and glutamine synthetase enzyme activities, and plastid pigment content. Journal of Plant Nutrition, v.18, p.1281-1290, 1995.

TIMPO, E.E.; NEYRA, C.A. Expression of nitrate and nitrite reductase activities under various forms of nitrogen nutrition in Phaseolus vulgaris L. Plant Physiology, v.72, p.71-75, 1983.

URQUIAGA, S.; BOTTEON, P.B.L.; BODDEY, R.M. Selection of sugarcane cultivars for associated biological nitrogen fixation using ${ }^{15} \mathrm{~N}$-labelled soil. In: INTERNATIONAL SYMPOSIUM ON NITROGEN FIXATION WITH NON-LEGUMES, 4., 1987. Proceedings. Rio de Janeiro: Developments in Plant and Soil Sciences, 1989. p.311-319.

URQUIAGA, S.; CRUZ, K.H.S.; BODDEY, R.M. Contribution of nitrogen fixation to sugarcane: nitrogen - 15 and nitrogen - balance estimates. Soil Science Society of America Journal, v.56, p.105114, 1992.

WHITHAM, F.H.; BLAYDES, D.F.; DEVLIN, R.M. Experiments in plant physiology. New York: D. Van Nostrand Company, 1971. p.55-58.

ZAGO, V.C.P. Estudos da aplicação de esterco bovino e uréia nos compostos nitrogenados solúveis em tecidos foliares e na produção de couve. 1997. 109p. Dissertação (Mestrado) Universidade Federal Rural do Rio de Janeiro, Seropédica.

Recebido em 13 de maio de 2004 e aprovado em 23 de agosto de 2004 